\title{
THÂN CHUNG ĐỘNG MẠCH KẾT HỢP VỚI GIÁN ĐOẠN ĐỘNG MẠCH CHỦ: ĐẶC ĐIỂM BỆNH LÝ VÀ CHIẾN LỰ̛C PHẪU THUẬT?
}

\author{
Nguyễn Anh Huy*, Đỗ Anh Tiến**, Phạm Thanh Tùng*, Nguyê̂n Bằng Việt**, \\ Nguyễn Trung Hiếu**, Phạm Tuấn Anh**, Đố Văn Tu**
}

\section{TÓM TẮT:}

Sự kết hợp của bất thường thân chung động mạch và gián đoạn động mạch chủ là một trong những thách thức lớn của phẫu thuật tim bẩm sinh. Báo cáo này trình bày một trường hợp phâuu thuật sửa toàn bộ thành công bằng tạo hình lại động mạch chủ lên, làm conduit động mạch phổi tại Trung tâm tim mạch bệnh viện $\mathrm{E}$. Qua trường hợp này, chúng tôi bàn luận về đặc điểm bệnh lý và phương pháp phẫu thuật đối với loại bất thường tim bẩm sinh phức tạp này và nhìn lại $\mathrm{y}$ văn thế giới.

Tù khóa: thân chung động mạch, gián đoạn động mạch chủ

\section{SUMMARY:}

The associationof truncus arteriosuswith interrupted aortic arch represents a formidable surgical challenge. This report presents a successful repair using a technique that allows the widelypatent ductus arteriosus to maintain continuity betweenthe truncus (with pulmonary arteries detached) and thedescending aortain Cardiac Center- E hospital.Furthermore, we will discuss surgical technique and summarize published information about this procedure.

Keywords: truncus arteriosus, interrupted aortic arch

\section{I. ĐẶT VẤN ĐỀ}

Thân chung TruncusarteriosusCommunis - TA ) là một bất thường tim bẩm sinh với tỷ lệ mắc khoảng $0.7 \%$ trong số các bệnh tim bẩm sinh [1]. Gián đoạn cung động mạch chủ ( Aortic arch interruption - IAA) được tìm thấy khoảng $15 \%$ những đứa trẻ này $[2,3]$. Vì vậy, sự kết hợp của 2 tổn thương này trên cùng một bệnh nhân là một bất thường rất hiếm gặp.

Gomes và McGoon đã báo cáo trình bày phẫu thuật thành công sự kết hợp của hai tổn thương này vào năm 1971 [4]. Sau đó, có rất ít các thông báo lâm sàng trong vài thập kỷ qua đề cập đến tổn thương và phương pháp phẫu thuật đối với sự kết hợp của 2 tổn thương này. Năm 2006, Igor E. Konstantino và Tara Karamlou đã báo cáo 50 trường hợp trong 10 năm điều trị bệnh lý này ở trung tâm của họ, đề cập đến các vấn đề về đặc điểm lâm sàng, quản lý và điều trị phẫu thuật với nhóm bệnh nhân này.[5]

Với sự phức tạp của bệnh lý và tỷ lệ hiếm gặp của nó, điều trị phẫu thuật đặt ra một thách thức lớn đối với các phẫu thuật viên tim mạch. Tại Việt Nam, chưa có một thông báo lâm sàng nào đề cập đến phẫu thuật đối với những trường hợp này. Mục tiêu của thông báo này là đề cập đến đặc điểm bệnh lý, đặc điểm phẫu thuật và bàn luận về phương pháp phẫu thuật của bất thường này.

\section{GIỚI THIẾU CA LÂM SÀNG}

Bệnh nhân nam, 7 tháng tuổi, con lần 4, PARA 3012 ( 1 trường hợp sảy thai con lần 2 , con lần 3 chết khi 1 tháng tuổi không rõ nguyên nhân). Tiền sử: đẻ thường, cân nặng lúc sinh $2700 \mathrm{gr}$, trong 7 tháng bệnh nhân đã điều trị viêm phổi nhiều đợt. Đợt này trẻ đang điều trị viêm phổi ngày thứ 6 tại bệnh viện tỉnh, vào Trung tâm Tim mạch Bệnh viện $\mathrm{E}$ trong tình trạng: Tỉnh, có hội chứng nhiễm trùng, tự thở, ho khan, tím khi ho, khó thở ( nhịp thở 40 lần/ phút), phổi có rales ẩm, ran rít 2 phổi, tim có tiếng thổi tâm thu vị trí cạnh ức trái khoang liên sườn III.

\section{X - quang: Bóng tim to}

Kết quả siêu âm tim: Thân chung động mạch, động mạch chủ và động mạch phổi xuất

\footnotetext{
* Trưòng đại học Y Hà Nội

** Trung tâm Tim mạch Bệnh viện E

Ngưòi chịu trách nhiệm khoa họ: BS Nguyễn Anh Huy

Ngày nhận bài: 01/11/2019 - Ngày Cho Phép Đăng: 20/12/2019

Phản Biện Khoa học: PGS.TS. Đặng Ngoc Hùng
}

GS.TS. Lê Ngoc Thành 
phát từ thân chung, vị trí chia nhánh động mạch phổi xuất phát từ thân chung, TLT rộng KT $14 \mathrm{~mm}$ shunt 2 chiều, thân chung cưỡi ngựa trên vách liên thất $50 \%$, hở van thân chung mức độ vừa, còn ống động mạch, tăng áp lực động mạch phổi nặng. Gián đoạn quai động mạch chủ, vị trí gián đoạn vị trí giữa động mạch cảnh gốc trái và động mạch dưới đòn trái.

Bệnh nhân được chỉ định phẫu thuật với chẩn đoán: Gián đoạn quai động mạch chủ type $\mathrm{B}$, thân chung động mạch type I. Phẫu thuật ngày 25/09/2019.

\section{Cách thức phẫu thuật:}

+ Tư thế bệnh nhân trong mổ: Nằm ngửa, hai tay khép dọc thân mình.

+ Thiết lập hệ thống tuần hoàn ngoài cơ thể: Đặt ống động mạch vào vị trí thân cánh tay đầu, đặt ống tĩnh mạch vào tĩnh mạch chủ trên và chủ dưới, khống chế hai động mạch phổi trước khi chạy máy tim phổi nhân tạo, khống chế các động mạch nuôi não.

+ Bảo vệ cơ tim: Liệt tim qua gốc động mạch chủ bằng dung dịch Custodiol, hạ nhiệt độ đến 28 độ $\mathrm{C}$.

\section{phẫu thuật: \\ Mô tả tổn thương và các bước trong}

Phẫu tích động mạch chủ: Gián đoạn quai động mạch chủ type $\mathrm{B}$, vị trí gián đoạn giữa động mạch cảnh gốc trái và động mạch dưới đòn trái. Thân chung động mạch type I, ống động mạch từ thân chung cấp máu vào cho động mạch cảnh gốc trái và động mạch dưới đòn trái, động mạch vành phải xuất phát từ mặt trước và cách xa vòng van động mạch $10 \mathrm{~mm}$. Sau khi thiết lập, chạy hệ thống tuần hoàn ngoài cơ thể và liệt tim, tiến hành: Tạo hình lại quai động mạch chủ: Cắt đoạn xuống khỏi thân chung, phẫu tích, xẻ dọc quai đoạn động mạch dưới đòn trái, nối lại vào quai động mạch chủ. Sửa toàn bộ thân chung: Cắt đoạn chạc ba động mạch phổi khỏi động mạch chủ, mở phễu thất phải, vá lỗ thông liên thất, khâu lại chỗ mở động mạch chủ, nối thất phải và động mạch phổi bằng 01 conduit $14 \mathrm{~mm}$. Cầm máu, đặt các dẫn lưu, đóng lại màng tim, đóng xương ức, đóng lại vết mổ theo các lớp giải phẫu.

Tổng thời gian phẫu thuật là 180 phút, thời gian chạy tuần hoàn ngoài cơ thể 120 phút, kẹp động mạch chủ 90 phút.

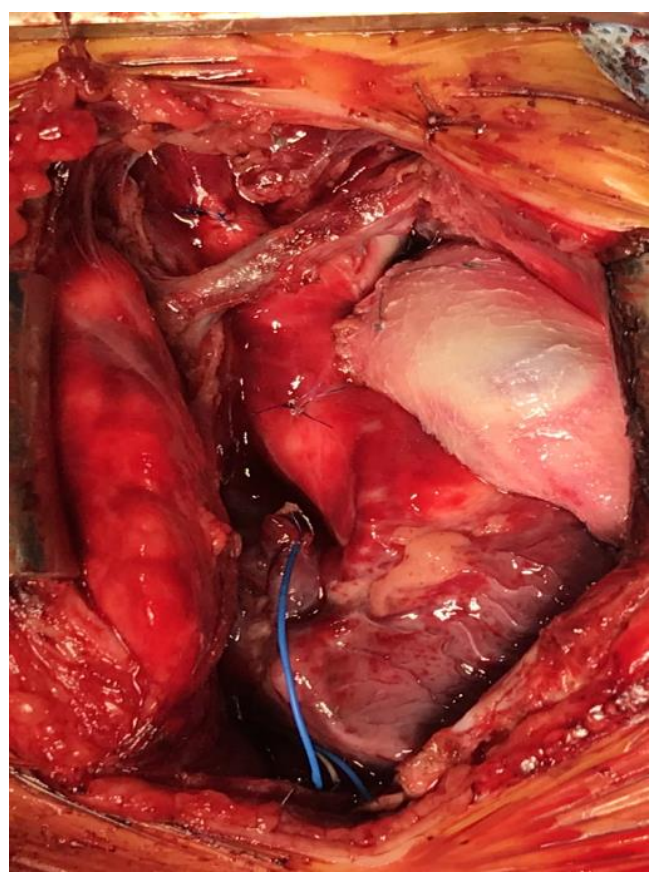

Hình 1. Sau phẫu thuật sửa toàn bộ tổn thuoong thân chung động mạch và gián đoạn quai động mạch chủ 


\section{Diễn biến hậu phẫu:}

Sau mổ bệnh nhân được chuyển về đơn vị hồi sức, thở máy 4 ngày, dùng 01 thuốc vận mạch liều trung bình ( ngừng vận mạch sau 01 ngày), điều trị kháng sinh, giảm đau, chống đông. Bệnh nhân được rút dẫn lưu sau 5 ngày. Bệnh nhân ra phòng hậu phẫu thường vào ngày thứ 9 sau mổ.

Siêu âm tim sau mổ: TLT kín không còn shunt tồn lưu, đường ra thất phải thông thoáng, van ĐMC hở hẹ, eo và quai ĐMC thông thoáng. Conduit ĐMP hoạt động tốt, chênh áp $4 \mathrm{mmHg}, 2$ gốc nhanh ĐMP thông thoáng, chức năng tâm thu thất trái trong giới hạn bình thường.

\section{Bệnh nhân ra viện sau 14 ngày.}

\section{BÀN LUẬn}

\subsection{Phân loại}

\subsubsection{Phân loại thân chung động mạch}

Collet và Edwards [6] đã phân loại dị tật thân chung động mạch theo nguồn gốc giải phẫu của các động mạch phổi và mối quan hệ không gian giữa các mạch này (Bảng 1). Năm 1965, Van Praagh đã đề xuất một phân loại giải phẫu khác, trong phân loại này cũng nhắc đến sự hiện diện hay không của tổn thương thông liên thất liên quan đến thân chung động mạch (Bảng 2) [7].
Gần đây hơn, Hiệp hội Phẫu thuật Tim mạch Châu Âu đã đề xuất một hệ thống danh pháp thân chung động mạch thống nhất sử dụng trong cơ sở dữ liệu phẫu thuật, dựa trên phân loại được đề xuất bởi Van Praagh [7] năm 1976 ( Bảng 3). Danh pháp mới này được đề xuất dựa trên các quan điểm rằng: (1) Mô tả nguồn gốc của các nhánh động mạch phổi phải và trái từ thân chung động mạch dựa trên chụp động mạch và siêu âm tim, thường không phù hợp với sự xuất hiện trong quá trình phẫu thuật; (2) Ngay cả khi đánh giá trước phẫu thuật cho thấy sự hiện diện của một phần hình thành vách ngăn động mạch chủ, phẫu thuật viên hiếm khi có thể cô lập và tách riêng được đoạn động mạch phổi; và (3) các trường hợp hiếm gặp của thân chung động mạch mà không có thông liên thất ( trong phân loại của Van Praagh) thường được kết hợp với dính liền động mạch chủ và van ĐMP, hoặc van ĐMP lớn và thiểu sản động mạch chủ; do đó, chúng có thể không đại diện cho các trường hợp thực sự của thân chung động mạch, mà là các trường hợp còn ống động mạch lớn hoặc thiểu sản động mạch chủ. [8]

\section{Bảng 3.1. Phân loại thân chung động mạch theo Collett và Edwards}

\begin{tabular}{|c|l|}
\hline Type & \multicolumn{1}{|c|}{ Mô tả } \\
\hline I & $\begin{array}{l}\text { Một động mạch phổi chính ngắn, phát sinh từ phía sau của thân chung động mạch, chia } \\
\text { thành hai nhánh ĐMP phải và trái }\end{array}$ \\
\hline II & Hai động mạch phổi phát sinh từ phía sau của thân chung, liền kề nhau \\
\hline III & Hai động mạch phổi phát sinh từ hai bên phía sau của thân chung, cách xa nhau \\
\hline IV & $\begin{array}{l}\text { Không có các động mạch phồi, phối được cấp máu bới các động mạch bàng hệ có nguồn } \\
\text { gốc từ ĐMC xuống }\end{array}$ \\
\hline
\end{tabular}

Bảng 3.2. Phân loại thân chung động mạch theo Van Praagh

\begin{tabular}{|l|l|}
\hline Type & Mô tả \\
\hline 1 & Vách ngăn chủ phổi được hình thành một phần, do đó có một đoạn ĐMP chính \\
\hline 2 & $\begin{array}{l}\text { Hoàn toàn không có vách ngăn, do đó không có động mạch phối chính được hình thành, } \\
\text { cả } 2 \text { nhánh ĐMP phát sinh trực tiếp từ thân chung, khoảng cách của các động mạch phồi } \\
\text { không có ý nghĩa }\end{array}$ \\
\hline 3 & $\begin{array}{l}\text { Một động mạch phổi phát sinh từ thân chung, nhánh động mạch phổi khác có nguồn gốc } \\
\text { từ động mạch chủ xuống }\end{array}$ \\
\hline 4 & Sự phát triển của quai động mạch chủ liên quan đến một ống động mạch lớn \\
\hline
\end{tabular}


Phân loại này cũng đề cập đến sự hiện diện ( nhóm $\mathrm{A}$ ) hoặc vắng mặt ( nhóm $\mathrm{B}$ ) của khiếm khuyết thông liên thất. Do vậy, mỗi trường hợp của thân chung động mạch được đề cập đến bằng một danh pháp bao gồm một chữ cái và một chữ số.

Bảng 3.3. Phân loại thân chung động mạch theo Hiệp hội Phẫu thuật Tim mạch Châu Âu

\begin{tabular}{|l|l|l|}
\hline \multicolumn{1}{|c|}{$\begin{array}{c}\text { Phân loại Van Praagh cải tiến } \\
\text { (Hiệp hội Phấu thuật Tim mạch Châu Âu) }\end{array}$} & $\begin{array}{c}\text { Van } \\
\text { Praagh }\end{array}$ & \multicolumn{1}{c|}{$\begin{array}{c}\text { Collett và } \\
\text { Edwards }\end{array}$} \\
\hline $\begin{array}{l}\text { Nhóm 1: Thân chung động mạch với các động mạch phổi hợp lưu } \\
\text { hoặc gần hợp lưu ( loại ĐMC lớn) }\end{array}$ & A1, A2 & I, II, III \\
\hline $\begin{array}{l}\text { Nhóm 2: Thân chung động mạch và không có động mạch phổi ( loại } \\
\text { ĐMC lớn và không có ĐMP) }\end{array}$ & A3 & \\
\hline $\begin{array}{l}\text { Nhóm 3: Thân chung động mạch với quai ĐMC gián đoạn hoặc thiểu } \\
\text { sản nghiêm trọng ( Loại ĐMP lớn ) }\end{array}$ & A4 & \\
\hline
\end{tabular}

Như vậy, tổn thương trong bệnh nhân của chúng tôi nhằm trong nhóm 3 trong phân loại Van Praagh cải tiến của Hiệp hội Phẫu thuật Tim mạch Châu Âu.

\subsubsection{Phân loại gián đoạn quai động mạch chủ}

Theo Celoria và Patten [9], gián đoạn quai động mạch chủ chia làm 3 loại chính, trên cơ sở bất thường giải phẫu cụ thể. Bao gồm:

- Type A: Quai động mạch chủ bị gián đoạn sau động mạch dưới đòn trái

- Type B: Quai động mạch chủ bị gián đoạn giữa động mạch cảnh chung trái và động mạch dưới đòn trái. Đây là dạng phổ biến nhất của bệnh lý này.

- Type C: Quai động mạch chủ bị gián đoạn giữa thân động mạch cánh tay đầu và động mạch cảnh chung trái. Đây là dạng ít gặp nhất.
Mỗi type phân loại có thể chia thành hai nhóm nhỏ, dựa trên việc liệu động mạch dưới đòn phải có nguồn gốc ở vị trí giải phẫu bình thường (phân nhóm 1) hoặc nếu nó bắt nguồn từ xa động mạch dưới đòn trái và tiếp tục phía sau thực quản (phân nhóm 2). Tuy nhiên các phân nhóm này không ảnh hưởng đến cách chẩn đoán hoặc điều trị bệnh.

\subsubsection{Sự kết hợp hai tổn thương}

Năm 2006, Igor E. Konstantinov và cộng sự đã nghiên cứu nhóm bệnh nhân với sự kết hợp của hai tổn thương này, nhóm tác giả đã sử dụng phân loại của Collett và Edwards ( có cải tiến) và phân loại của Celoria và Patten để chia các bệnh nhân của họ thành các nhóm khác nhau ( Hình 2). [5].

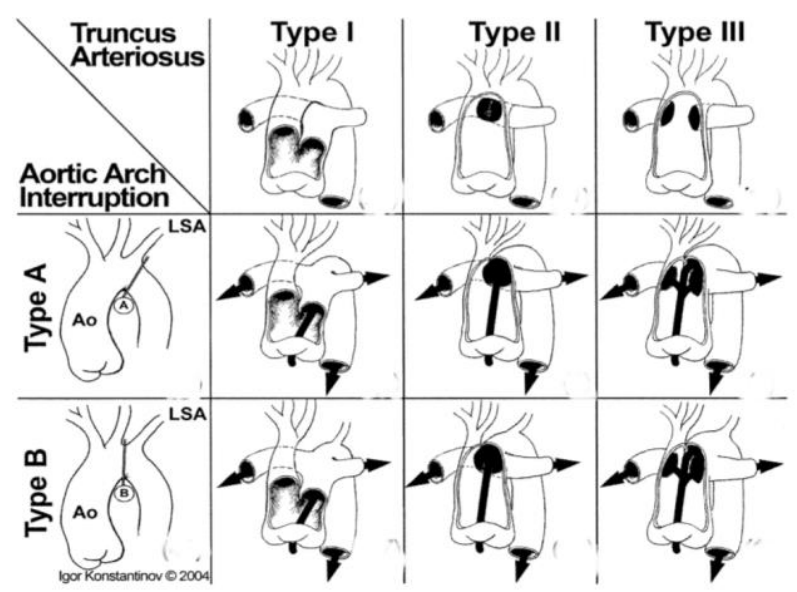

Hình 2. Các nhóm tổn thương phối hợp theo nghiên cứu của Igor E. Konstantinov và cộng sụ [5] 
Theo các tác giả này, không có bệnh nhân nào có sự kết hợp với tổn thương gián đoạn quai động mạch chủ type $\mathrm{C}$, tỷ lệ loại tổn thương gặp nhiều nhất là tổn thương thân chung type I và tổn thương gián đoạn quai động mạch chủ type B.[5] Trường hợp bệnh nhân của chúng tôi cũng có tổn thương phối hợp loại này.

\subsection{Bàn luận về phương pháp phẫu thuật}

Để điều trị bệnh lý phối hợp giữa hai bất thường thân chung động mạch và gián đoạn động mạch chủ, phẫu thuật là lựa chọn quan trọng nhất, điều trị nội khoa trước và sau mổ đóng vai trò hỗ trợ. $100 \%$ bệnh nhân nếu được chẩn đoán bệnh lý này tử vong nếu không được phẫu thuật. Mục tiêu của điều trị phẫu thuật bao gồm tách biệt tim phải và tim trái đảm bảo lưu lượng máu không bị cản trở đến phổi và tuần hoàn hệ thống, tạo hình lại quai động mạch chủ về hình thái giải phẫu và sinh lý bình thường.[4]

Theo Igor E. Konstantinov và cộng sự [5], có các chiến lược phẫu thuật như sau:

- Sủa toàn bộ một giai đoạn: Bất thường thân chung động mạch và gián đoạn quai động mạch chủ được phẫu thuật sửa chữa cùng một ca mổ. Đây là phương án được sử dụng nhiều nhất. Tỷ lệ tử vong sau mổ khi lựa chọn phương án này theo báo cáo của Igor E. Konstantinov và cộng sự khoảng $47 \%$.

- Sưa chũa hai giai đoạn: Gián đoạn quai động mạch chủ được phẫu thuật trước, sau đó phẫu thuật điều trị thân chung động mạch được tiến hành trong lần nhập viện thứ 2 , tỷ lệ tử vong theo phương án này là $86 \%$.

- Các loại sủa chũa khác: Trường hợp bệnh nhân vị hội chứng thiểu sản tim trái (HLHS) được tiến hành phẫu thuật Norwood và ghép tim.

- Phẫu thuật diều trị gián đọ̣n động mạch chủ: Các bệnh nhân được sửa chữa bằng phẫu thuật trực tiếp (có hoặc không sử dụng miếng vá tăng cường và tạo hình. Một số ít cần ghép đoạn động mạch.
- Phẫu thuật van động mạch: Ở những trường hợp có tổn thương van thân chung mức độ nặng ( hở van ) cần tiến hành phẫu thuật sửa van hoặc thay van.

- Phẫu thuật sửa thân chung động mạch: Động mạch phổi được tách rời khỏi thân chung, đóng lại động mạch chủ có thể trực tiếp hoặc sử dụng miếng vá nhân tạo. Một ống nối động mạch có van (conduit) nối giữa phễu thất phải và động mạch phổi để tái lập tuần hoàn động mạch phổi.

Bệnh nhân của chúng tôi đã được tiến hành phẫu thuật sửa toàn bộ trong cùng một lần mổ, tạo hình lại quai động mạch chủ, sử dụng conduit và vá thông liên thất đồng thời trong mổ, đây là những kỹ thuật phức tạp nếu thực hiện trong cùng một thì [4], [5]. Thời gian phẫu thuật và thời gian chạy máy tim phổi nhân tạo ở bệnh nhân của chúng tôi là 120 phút, thấp hơn các tác giả thông báo, thời gian này theo thống kê của Igor $\mathrm{E}$. Konstantinov và cộng sự ngắn nhất là 139 phút và dài nhất 271 phút. Tuy vậy, sửa chữa một giai đoạn được các tác giả khuyến cáo lựa chọn đầu tiên để tránh các nguy cơ của một suy tim tiềm tàng, và do đó, tỷ lệ tử vong khi lựa chọn phương án này thấp hơn. Kết quả siêu âm sớm sau mổ cho thấy đây là một sửa chữa tốt.

Tỷ lệ sống sót sau khi được điều trị phẫu thuật 6 tháng là $44 \%, 1$ năm là $39 \%$ và $31 \%$ sau 10 năm. Yếu tố liên quan tăng nguy cơ tử vong bao gồm: Nữ giới, thân chung động mạch type III [5]. Bệnh nhân của chúng tôi không có các yếu tố tăng thêm nguy cơ tử vong này. Thời gian điều trị hậu phẫu ngắn do nhiều yếu tố mang lại, trong đó trình độ phẫu thuật viên, kỹ thuật và phương tiện hồi sức đóng vai trò quan trọng.

\section{KẾT LUẬN}

Thân chung động mạch và gián đoạn động mạch chủ là một sự phối hợp các bất thường phức tạp. Tỷ lệ tử vong sớm cao đã đem lại thách thức cho các phẫu thuật viên. Lựa chọn phẫu thuật sửa toàn bộ trong cùng một thì mổ là phương án hợp lý cho kết quả sửa chữa tốt, cải thiện tiên lượng sống cho các bệnh nhân. 


\section{TÀI LIÊU THAM KHẢO}

1. Keith JD. Prevalence, incidence, and epidemiology (1978). In: KeithJD, Rowe RD, Vlad P, eds. Heart disease in infancy andchildren. 3rd ed. New York, NY: Macmillan;3-13.

2. Van Praagh R, Van Praagh S (1965). The anatomy of commonaorticpulmonary trunk (truncus arteriosus communis) andits embryologic implications. Am J Cardiol ;16:406-25.

3. Van Praagh R (1987). Truncus arteriosus: what is it and how shouldit be classified? Eur J Cardiothorac Surg; 1:65-70.

4. Gomes MMR, McGoon DC (1971). Truncus arteriosus with interruption of the aortic arch: report of a case successfullyrepaired. Mayo Clin Proc;46:40-3.

5. Igor E. Konstantinov, MD, PhD, Tara Karamlou, MD, Eugene H. Blackstone,MD (2006). Truncus Arteriosus Associated with
InterruptedAortic Arch in 50Neonates: A Congenital HeartSurgeons Society Study. Ann Thorac Surg;81:214-23

6. Collett RW, Edwards JE (1949). Persistent truncus arteriosus, a classification according to anatomic types. SurgClinNorth Am; 29:1245-1270.

7. Van Praagh R (1976). Editorial: Classification of truncus arteriosus communis (TAC). Am.Heart J. 92:129-132.

8. Jacobs ML (2000). Congenital Heart Surgery Nomenclature and Database Project: truncus arteriosus. AnnThoracSurg; 69:S50-S55.

9. Celoria GC, Patton RB (1959). Congenital absence of the aortic arch. Am Heart J ;58:407-13. 